\title{
RESEARCH
}

Open Access

\section{Predictive value of lymphocytopenia and the neutrophil-lymphocyte count ratio for severe imported malaria}

Marlies E van Wolfswinkel ${ }^{1}$, Klaske Vliegenthart-Jongbloed ${ }^{1}$, Mariana de Mendonça Melo ${ }^{1}$, Peter C Wever ${ }^{2}$, Matthew B McCall ${ }^{3}$, Rob Koelewijn ${ }^{4}$, Jaap J van Hellemond ${ }^{3,4}$ and Perry J van Genderen ${ }^{1,5,6^{*}}$

\begin{abstract}
Background: Lymphocytopenia has frequently been described in patients with malaria, but studies on its association with disease severity have yielded conflicting results. The neutrophil/lymphocyte count ratio (NLCR) has been introduced as a parameter for systemic inflammation in critically ill patients and was found, together with lymphocytopenia, to be a better predictor of bacteraemia than routine parameters like C-reactive protein and total leukocyte count. In the present study, the predictive value of the NLCR and lymphocytopenia for severe disease was evaluated in patients with imported malaria.
\end{abstract}

Methods: All patients diagnosed with malaria at the Harbour Hospital between January $1^{\text {st }} 1999$ and January $1^{\text {st }}$ 2012 with differential white cell counts determined within the first 24 hours after admission were included in this retrospective study. Severe malaria was defined according to the WHO criteria. The performance of the NLCR and lymphocytopenia as a marker of severe malarial disease was compared back-to-back with that of C-reactive protein as a reference biomarker.

Results: A total of 440 patients (severe falciparum malaria $n=61$, non-severe falciparum malaria $n=259$, nonfalciparum malaria $\mathrm{n}=120$ ) were included in the study. Lymphocytopenia was present in $52 \%$ of all patients and the median NLCR of all patients was 3.2. Total lymphocyte counts and NLCR did not differ significantly between groups. A significant correlation of total leukocyte count and NLCR, but not lymphocyte count, with parasitaemia was found. ROC analysis revealed a good negative predictive value but a poor positive predictive value of both lymphocytopenia and NLCR and performance was inferior to that of C-reactive protein. After complete parasite clearance a significant rise in total leukocyte count and lymphocyte count and a significant decrease in NLCR was observed.

Conclusion: The NLCR was found to correlate with parasitaemia, but both lymphocytopenia and the NLCR were inferior to C-reactive protein as markers for severe disease in patients with imported malaria. The NLCR and lymphocytopenia are not useful as predictive markers for severe disease in imported malaria in the acute care setting.

Keywords: Malaria, Severity, Falciparum, NLCR, Lymphocytopenia, Leukocyte count, Severe disease, Marker, Biomarker

\footnotetext{
*Correspondence: p.van.genderen@havenziekenhuis.nl

'Department of Internal Medicine, Harbour Hospital Rotterdam, Rotterdam,

The Netherlands

${ }^{5}$ Institute for Tropical Diseases, Harbour Hospital Rotterdam, Haringvliet 72,

3011, TG Rotterdam, The Netherlands

Full list of author information is available at the end of the article
} 


\section{Background}

Changes in blood cell counts are a well-known feature of malaria. Alterations in leukocyte counts are often less pronounced than in the other blood cell lineages, but in general total leukocyte counts have been found to be low to normal in malaria [1,2]. Lymphocytopenia has frequently been described in malaria patients in endemic areas [3-6], and was found to be present in $63 \%$ of patients with imported Plasmodium falciparum infection [7]. Studies on the correlation between lymphocyte count and malaria severity yielded conflicting results, as both lymphocytopenia $[1,3,4]$ and lymphocytosis [8] have been reported to be associated with adverse outcome.

Lymphocytopenia accompanied by a rise in neutrophil count is commonly seen in various infectious and noninfectious causes of systemic inflammation and stress [9-13]. Zahorec et al. introduced the ratio of neutrophil to lymphocyte count as a parameter of systemic inflammation and stress in critically ill surgical and medical patients [14]. The predictive value of both lymphocytopenia and the neutrophil-lymphocyte count ratio (NLCR) for bacteraemia was confirmed in a study in an emergency care setting, in which these parameters were found to be better predictors of bacteraemia than routine parameters like C-reactive protein (CRP) level, total leukocyte count or neutrophil count. Recently, another study evaluated this parameter in patients with a community-acquired pneumonia (CAP) [15] and it was found to predict severity and outcome of CAP with a higher prognostic accuracy as compared with traditional infection markers.

Although the NLCR is currently not routinely used as a clinical parameter, the above mentioned studies have demonstrated its value as an infection marker in critically ill patients. Unequivocal data concerning the predictive value of lymphocytopenia and the NLCR in malaria are not yet available.

In non-endemic countries, where malaria is only seen as an imported disease, non-specialized hospitals often rely on rapid diagnostic tests for the diagnosis of malaria and generally lack experience in the examination of thick and thin blood smears to asses the parasite load. There is, therefore, still a need for simple and readily available parameters for the early identification of patients at risk of severe or complicated disease. The present study evaluated lymphocytopenia and the NLCR as predictive markers of severe disease in a large cohort of patients with imported malaria.

\section{Methods}

\section{Patients}

The Harbour Hospital is a 161-bed general hospital located in Rotterdam, The Netherlands. It also comprises the Institute of Tropical Diseases, which serves as a national referral centre. All patients diagnosed with malaria at our centre are included in the Rotterdam Malaria Cohort study. Demographic, clinical and laboratory data of all these patients are collected using a standardized form and stored in an electronic database. For the present observational cohort study, patients diagnosed with malaria between January $1^{\text {st }} 1999$ and January $1^{\text {st }} 2012$ and with differential white cell counts determined within the first 24 hours after admission were included.

\section{Laboratory investigations}

Total and differential leukocyte counts were measured using an automatic cell counters. During the study period three distinct cell counters were subsequently used after careful calibration (Sysmex NE 8000 [in the period January 1st 1999 -July 31st 2002], Beckman Coulter HMX [July 31st 2002- July 31st 2010] and Sysmex XE 2100 [July 31st 2010 - January 1st 2012], respectively). Absolute numbers of lymphocytes and neutrophil subsets were obtained by multiplication of the absolute leukocyte counts with their respective differential leukocyte counts. Manual confirmation of automatic cell count results was performed when immature or aberrant leukocytes, erythrocytes or platelet clumps were detected and when cell count results differed substantially from normal values. Other available laboratory examinations included red blood cell counts, haematocrit, platelet counts, C-reactive protein levels, serum electrolytes, total bilirubin, serum creatinine and urea, sodium, potassium, liver enzymes, blood glucose and venous plasma lactate.

\section{Detection of Plasmodium parasites}

The standard procedure to diagnose malaria comprised a Quantitative Buffy Coat (QBC) analysis, a rapid diagnostic test (RDT) for malaria antigens (Binax NOW ${ }^{\circledR}$ Malaria Test Binax, Inc. Maine, USA), and thick and thin blood smears using freshly collected blood specimens from finger pricks. The RDT and the QBC analysis were performed according to the manufacturer's instructions. QBC capillaries were examined independently by two technicians by microscopic analysis of two complete rows of the region between the bottom of the capillary and the polynuclear leukocyte layer using an Olympus BX-60 fluorescence microscope equipped with UV-filter, $50 \mathrm{x}$ objective and $12.5 \mathrm{x}$ oculars (total magnification $625 \mathrm{x}$ ). These two lanes represent about 100 microscopic fields (at $625 \times$ magnification) and take an average examination time of $5 \mathrm{~min}$. Subsequently, the polynuclear and mononuclear cell layer was screened for schizonts, gametocytes, malaria pigment and elderly trophozoites of Plasmodium vivax and Plasmodium ovale.

Thick blood smears were stained with Field's stain (Brunschwig Chemie, Amsterdam, the Netherlands) and thin smears with Diff Quick stain (Medion Diagnostics, 
Düdingen, Switzerland). Both staining procedures have been optimized for optimal staining of Plasmodium parasites as well as Schüffner's dots and Maurer's clefts in infected erythrocytes. Thick and thin smears were examined with regular light microscopes at a total magnification of $1250 \mathrm{x}$.

The same Plasmodium detection methods were used throughout the whole study period.

\section{Definitions}

\section{Severe malaria}

Patients were classified as having severe malaria if they met one or more of the WHO criteria for severe malaria, as published [16], either on presentation or later during hospital admission.

\section{Leukocyte counts and NLCR}

Leukocytopenia was defined as a leukocyte count of less than $4.0 \times 10^{9} / \mathrm{L}$ and leukocytosis was defined as a leukocyte count exceeding $10.0 \times 10^{9} / \mathrm{L}$. Lymphocytopenia was defined as a lymphocyte count of less than $1.0 \times 10^{9} / \mathrm{L}$ and lymphocytosis as a lymphocyte count more than $4.0 \times 10^{9} / \mathrm{L}$. Neutropenia was defined as a neutrophil count of less than $1.5 \times 10^{9} / \mathrm{L}$ and neutrophilia as a neutrophil count of more than $7.0 \times 10^{9} / \mathrm{L}$. The neutrophillymphocyte count ratio was defined as the ratio of the absolute neutrophil count to the absolute lymphocyte count.

\section{Estimation of immunity to $P$. falciparum}

The degree of immunity to malaria was estimated as previously described [17]. Adult immigrants from a malaria-endemic country living in the Netherlands were considered partially immune, because they had likely been exposed to $P$. falciparum during childhood. Patients who had been living in a malaria-endemic area for at least 2 years at the time of diagnosis were presumed semi-immune. Tourists from non-endemic regions who travelled to endemic areas were considered non-immune.

\section{Statistical analysis}

Data were not normally distributed (Kolmogorov-Smirnov test) and are therefore presented as medians and range. Univariate comparisons were performed using the ChiSquare test and the Kruskall-Wallis test with Dunn's posthoc tests (three groups), or the Mann-Whitney test and Fisher's Exact test (two groups). Correlations with parasitaemia were calculated using Spearman's rank correlation. For the comparisons of differential leukocyte counts before and after treatment, Wilcoxon's matched pairs test was used.

For clinical reference, the diagnostic performance of NLCR and lymphocytopenia for severe disease was compared to that of the classic biomarker serum CRP using receiver operating characteristic (ROC) analysis. The optimal cut-off point was identified using Youden's index. The areas under the ROC curve (AUROCs) were compared to that of CRP in a pair-wise comparison by the method of Hanley and McNeil [18].

\section{Ethical approval}

Given its retrospective observational design, ethical approval of this study was not required, according to the Dutch Medical Research Involving Human Subjects Act.

\section{Results}

\section{Patient characteristics}

Between January $1^{\text {st }} 1999$ and January $1^{\text {st }} 2012$ a total of 562 cases of imported malaria were seen. Differential leukocyte counts were available for 440 (78\%) of the patients. Of these cases, 120 cases were caused by nonfalciparum Plasmodium species: 88 by $P$. vivax, 27 by $P$. ovale, four by Plasmodium malariae and one by Plasmodium knowlesi. The majority of infections (320 or $72 \%$ ) was caused by $P$. falciparum, including three patients who had a mixed infection; two with $P$. falciparum and $P$. ovale, one with $P$. falciparum and $P$. vivax. Sixty-one patients were classified as having severe malaria. All these patients met the severity criteria upon admission to the hospital, and no patients were re-classified as having severe malaria because of progression of disease during admission. Concomitant infection was present in $29(7 \%)$ of patients and was more common in patients with severe malaria. None of the patients had positive blood cultures. The general characteristics of these patients are shown in Table 1.

\section{Leukocyte counts and NLCR}

Leukocytopenia was present in 23\% (100/440) of all patients but in only $11 \%(7 / 61)$ of patients with severe malaria (Figure 1). Leukocytosis was seen in 4\% (19/440) of all patients and was more common in patients with severe disease $(13 \%$ or $8 / 61)$ compared to those with non-severe falciparum malaria $(2 \%$ or $6 / 259)$ and nonfalciparum malaria ( $4 \%$ or $5 / 120)$. Likewise, leukocyte counts were higher in patients with severe malaria compared to those with non-severe $P$. falciparum malaria and non-falciparum malaria (Table 1).

Lymphocytopenia was present in 52\% (227/440) of all patients and was more frequently seen in patients with non-severe falciparum malaria $(143 / 259$ or $55 \%)$ than in patients with severe malaria $(28 / 61$ or $46 \%)$, and nonfalciparum malaria (54/120 or $45 \%)$. Absolute lymphocyte counts did not differ significantly between the three groups.

Neutropenia was found in $8 \%(36 / 440)$ of all patients and neutrophilia in $4 \%(17 / 440)$, but was more common 
Table 1 General characteristics

\begin{tabular}{|c|c|c|c|c|}
\hline & Severe P. falciparum & Non-severe P. falciparum & Non-falciparum & $P$ value \\
\hline & $n=61$ & $\mathrm{n}=\mathbf{2 5 9}$ & $n=120$ & \\
\hline Demographics & & & & \\
\hline Age, years & $44(4-70)$ & $39(11-78)$ & $36(15-77)$ & $0.0005^{*}$ \\
\hline Male/female, n (\%) & $39(64 \%) / 22(36 \%)$ & $191(74 \%) / 68(26 \%)$ & $83(69 \%) / 37(31 \%)$ & $N S^{\#}$ \\
\hline Immunity to $P$. falciparum & & & & $0.0029^{\#}$ \\
\hline Non-immune & $42(69 \%)$ & $123(47 \%)$ & N/A & \\
\hline Partially immune & 19 (31\%) & $118(46 \%)$ & N/A & \\
\hline Semi-immune & $0(0 \%)$ & $3(1 \%)$ & N/A & \\
\hline Unknown & $0(0 \%)$ & $16(6 \%)$ & N/A & \\
\hline Continent of acquisition & & & & $N S^{\#}$ \\
\hline Africa, n (\%) & $56(92 \%)$ & $240(93 \%)$ & $42(35 \%)$ & \\
\hline Asia, n (\%) & $3(5 \%)$ & $11(4 \%)$ & $50(42 \%)$ & \\
\hline South and Central America, n (\%) & $1(2 \%)$ & $5(2 \%)$ & $26(22 \%)$ & \\
\hline Unknown, n (\%) & $1(2 \%)$ & $3(1 \%)$ & $2(2 \%)$ & \\
\hline Duration of signs/symptoms & & & & $0.007^{\#}$ \\
\hline$<8$ days, $\mathrm{n}(\%)$ & $38(62 \%)$ & $177(68 \%)$ & $58(48 \%)$ & \\
\hline 8-14 days, $n$ (\%) & $17(28 \%)$ & $45(17 \%)$ & $24(20 \%)$ & \\
\hline 15-28 days, $\mathrm{n}(\%)$ & $2(3 \%)$ & $20(8 \%)$ & $11(9 \%)$ & \\
\hline$>28$ days, $\mathrm{n}(\%)$ & $0(0 \%)$ & $5(2 \%)$ & $8(7 \%)$ & \\
\hline Unknown, n (\%) & $4(7 \%)$ & $12(5 \%)$ & $19(16 \%)$ & \\
\hline Use of malaria chemoprophylaxis & & & & $<0.0001^{\#}$ \\
\hline No chemoprophylaxis, n (\%) & $49(80 \%)$ & $182(70 \%)$ & $51(43 \%)$ & \\
\hline Inadequate use, n (\%) & $8(13 \%)$ & $46(18 \%)$ & $15(13 \%)$ & \\
\hline Adequate use, n (\%) & $2(3 \%)$ & $20(8 \%)$ & $42(35 \%)$ & \\
\hline Unknown, n (\%) & $2(3 \%)$ & $11(4 \%)$ & $12(10 \%)$ & \\
\hline Vital signs on admission & & & & \\
\hline Body temperature, ${ }^{\circ} \mathrm{C}$ & $38.4(35.7-41.2)$ & $38.5(35.5-41.0)$ & $38.9(36.0-41.2)$ & $N S^{*}$ \\
\hline Pulse rate, beats per minute & $103(50-150)$ & $90(45-140)$ & $90(58-138)$ & $0.0005^{*}$ \\
\hline Systolic blood pressure, $\mathrm{mm} \mathrm{Hg}$ & $117(80-160)$ & $120(73-185)$ & $120(90-196)$ & N.T. \\
\hline Impaired consciousness (GCS<15), n (\%) & $8(13 \%)$ & $1(0 \%)$ & $0(0 \%)$ & N.T. \\
\hline Coma (GCS $\leq 11), n(\%)$ & $3(5 \%)$ & $0(0 \%)$ & $0(0 \%)$ & N.T. \\
\hline Laboratory data on admission & & & & \\
\hline Haemoglobin, mmol/L & $7.8(2.5-10.9)$ & $8.4(4.0-11.1)$ & $8.2(4.6-11.2)$ & N.T. \\
\hline Thrombocytes, $\times 10^{9} / \mathrm{L}$ & $39(3-188)$ & $101(18-293)$ & $95(10-292)$ & $<0.0001^{*}$ \\
\hline C-reactive protein, mg/L & $182(65-476)$ & $85(5-320)$ & $71(14-348)$ & $<0.0001^{*}$ \\
\hline Serum creatinine, $\mu \mathrm{mol} / \mathrm{L}$ & $114(39-1081)$ & $93(47-238)$ & $90(53-255)$ & N.T. \\
\hline Serum sodium, mmol/L & $131(115-146)$ & $135(119-145)$ & $135(124-148)$ & $<0.0001^{*}$ \\
\hline Lactate dehydrogenase, U/L & 485 (139-2038) & $268(118-947)$ & $246(127-775)$ & $<0.0001^{*}$ \\
\hline Total bilirubin, $\mu \mathrm{mol} / \mathrm{L}$ & $53(13-416)$ & $22(4-164)$ & $22(3-99)$ & N.T. \\
\hline Plasma lactate, $\mathrm{mmol} / \mathrm{L}$ & $2.3(0.6-6.2)$ & $1.4(0.5-4.6)$ & $1.3(0.6-4.0)$ & $<0.0001^{*}$ \\
\hline Leukocyte counts & & & & \\
\hline Total leukocyte count, $\times 10^{9} / \mathrm{L}$ & $6.9(2.5-18.5)$ & $4.9(1.3-13.4)$ & $5.3(1.9-15.3)$ & $<0.0001^{*}$ \\
\hline Neutrophil count, $\times 10^{9} / \mathrm{L}$ & $3.6(0.6-10.4)$ & $3.1(0.4-11.0)$ & $3.2(1.0-11.6)$ & $0.0064^{*}$ \\
\hline Neutrophil count $\%$ & $60(19-85)$ & $64(13-91)$ & $64(20-88)$ & $N S^{*}$ \\
\hline Lymphocyte count, $\times 10^{9} / \mathrm{L}$ & $1.0(0.2-4.2)$ & $0.9(0.1-5.0)$ & $1.1(0.3-6.1)$ & $N S^{*}$ \\
\hline
\end{tabular}


Table 1 General characteristics (Continued)

\begin{tabular}{|c|c|c|c|c|}
\hline Lymphocyte count \% & $15(4-45)$ & $19(2-74)$ & $21(5-74)$ & $0.0036^{*}$ \\
\hline NLCR & $3.5(0.7-17.0)$ & $3.3(0.2-46)$ & $2.8(0.3-17.6)$ & $N S^{*}$ \\
\hline \multicolumn{5}{|l|}{ Parasite count } \\
\hline P.falciparum load (asexual parasites/ $\mu \mathrm{L}$ ) & $230,000(520-1,380,600)$ & $4,288(2-208,000)$ & N/A & N.T. \\
\hline Presence of $P$. falciparum schizonts\%) & $33(54 \%)$ & $11(4 \%)$ & N/A & $<0.0001 \wedge$ \\
\hline \multicolumn{5}{|l|}{ Concomitant infection } \\
\hline All concomitant infections & $8(13 \%)$ & $11(4 \%)$ & $10(8 \%)$ & $<0.0001^{\#}$ \\
\hline Concomitant bacterial infection & $5(8 \%)$ & $3(1 \%)$ & $2(2 \%)$ & $0.004^{\#}$ \\
\hline
\end{tabular}

* Comparison of 3 groups using the Kruskal Wallis test, ${ }^{*}$ Comparison of 3 groups using the Chi-Square Test, $\wedge$ Comparison of 2 groups using Fisher's Exact test. Parameters that are included in the modified WHO severity criteria for severe falciparum malaria were not tested (N.T.).

in patients with severe malaria (7\% or 4/61) compared to those with non-severe falciparum malaria and nonfalciparum malaria (3\% or $7 / 259$ and $5 \%$ or $6 / 120$, respectively). Neutrophil counts were higher in patients with severe malaria compared to those with nonsevere $P$. falciparum malaria and non-falciparum malaria (Table 1).

The median NLCR of all patients was 3.2. Although there was a trend towards higher values in patients with severe malaria (3.5) compared to those with non-severe
P. falciparum (3.3) and non-falciparum (2.8) malaria, these differences were not significant.

\section{Correlation with parasitaemia}

Significant correlations were found between parasitaemia and total leukocyte count $\left(\mathrm{r}_{\mathrm{s}} 0.304, \mathrm{p}<0.0001\right)$ and parasitaemia and NLCR $\left(\mathrm{r}_{\mathrm{s}} 0.165, \mathrm{p}=0.03\right)$.

Correlations between parasitaemia and absolute lymphocyte or neutrophil counts were not significant.

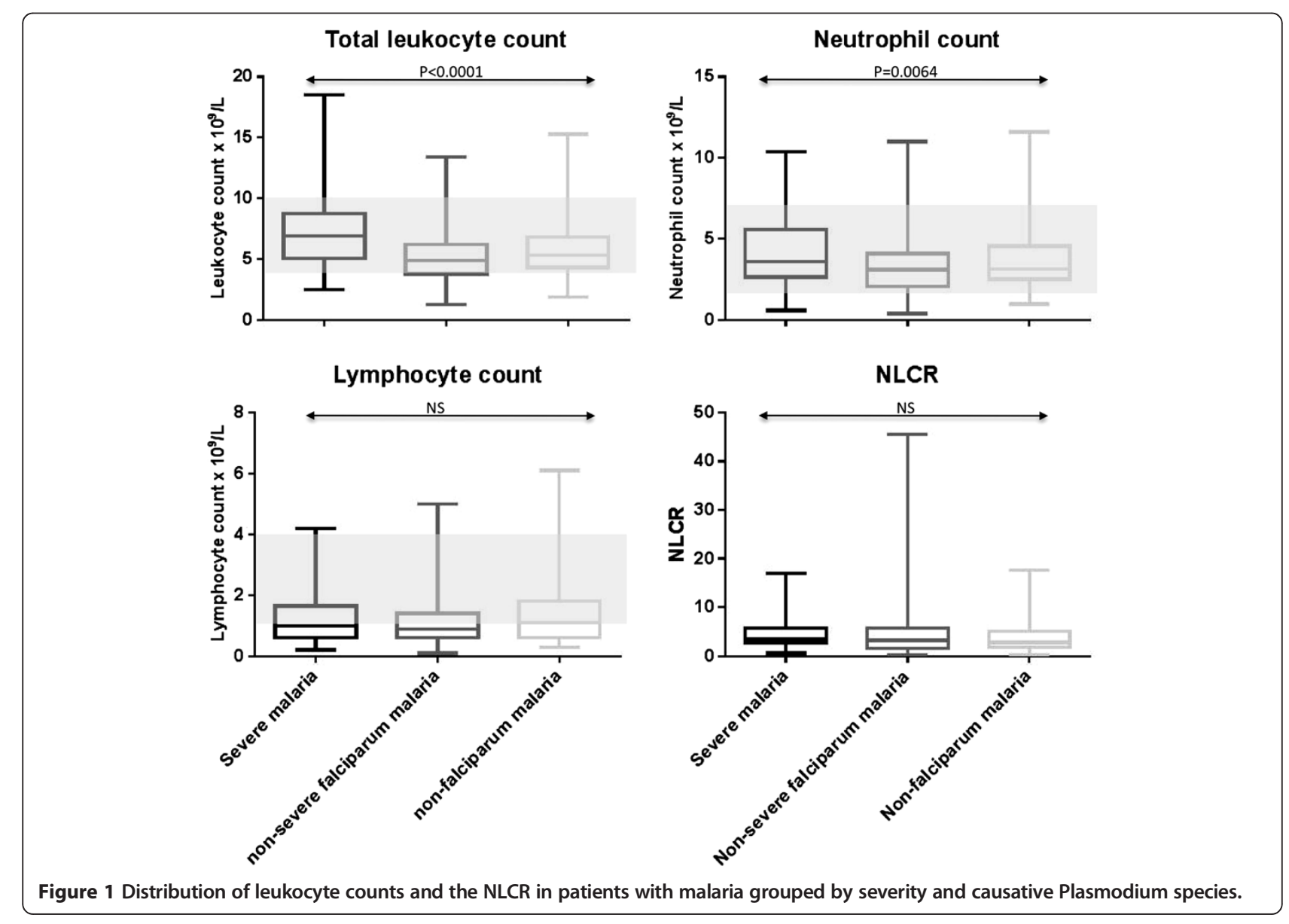


Table 2 Descriptive statistics of diagnostic performance for severe malaria

\begin{tabular}{|c|c|c|c|c|c|c|c|}
\hline Parameter & Cut-off value & Sensitivity & Specificity & PPV & NPV & Youden's & AUROC \\
\hline Total leukocyte count & $\geq 6.5 \times 10^{9} / \mathrm{L}$ & $0.59(0.46-0.71)$ & $0.75(0.71-0.80)$ & $0.28(0.21-0.37)$ & $0.92(0.88-0.95)$ & 0.34 & $0.70(0.63-0.78)$ \\
\hline Neutrophil count & $\geq 3.4 \times 10^{9} / \mathrm{L}$ & $0.64(0.51-0.76)$ & $0.56(0.51-0.61)$ & $0.19(0.14-0.25)$ & $0.91(0.86-0.94)$ & 0.2 & $0.61(0.53-0.69)$ \\
\hline Lymphocyte count & $<0.7 \times 10^{9} / \mathrm{L}$ & $0.33(0.22-0.46)$ & $0.72(0.67-0.76)$ & $0.16(0.10-0.24)$ & $0.87(0.83-0.90)$ & 0.05 & $0.51(0.43-0.59)$ \\
\hline NLCR & $\geq 2.8$ & $0.77(0.6$ & $44(0.39-0.49)$ & $0.18(0.14-0.24)$ & $0.92(0.87-0.96)$ & 0.21 & $0.57(0.50-0$ \\
\hline CRP & $>141 \mathrm{mg} / \mathrm{L}$ & $0.80(0.67-0.89)$ & $0.76(0.71-0.80)$ & $0.33(0.25-0.42)$ & $0.96(0.93-0.98)$ & 0.56 & $0.84(0.79-0.89)$ \\
\hline
\end{tabular}

\section{Predictive value and ROC analysis}

Analysis of the diagnostic performance of lymphocytopenia and the NLCR for the detection of severe malaria revealed good negative predictive value ( 0.87 and 0.92 respectively) but poor positive predictive value (Table 2). The AUROCs of total leukocyte count, neutrophil count, lymphocyte count and NLCR were all significantly inferior to that of CRP (Table 2).

\section{Leukocyte count changes during malaria treatment} Follow-up differential leukocyte counts were available for $40(66 \%)$ patients with severe malaria and 114 patients with non-severe $P$. falciparum infection. By the time of complete parasite clearance (confirmed by a negative $\mathrm{QBC}$ and thick blood smear) a significant rise in total leukocyte count and lymphocyte count and a significant decrease in NLCR was observed. A significant decrease in neutrophil counts after treatment was only seen in non-severe malaria patients, but not in patients with severe malaria (Table 3).

\section{Discussion}

In contrast to studies in bacterial sepsis, where lymphocytopenia and NLCR were found to outperform CRP in predicting the presence of bacteraemia, lymphocyte counts and NLCR did not allow for an accurate discrimination between malaria patients with severe disease and those without. Even though lymphocytopenia and NLCR had good negative predictive values, CRP was found to be a superior marker in back-to-back analyses.

This lack of diagnostic power might partly be due to the fact that neutrophilia, while often marked in patients with bacterial sepsis, is not commonly seen in malaria. Some studies even report neutropenia [1]. In the present study, neutrophil counts were in the lower range of normal. This is reflected in NLCR values that are much lower than those found in patients with bacteraemia [19] and might be an explanation for the dissimilar performance of the NLCR in bacterial sepsis and malaria. Bacterial coinfection was present in $8 \%$ of patients with severe malaria, which is consistent with the findings of a large cohort study on patients with severe malaria admitted to the ICU [20]. However, none of the patients in the present study had a positive blood culture. A major confounding effect of concomitant bacterial infections is, therefore, unlikely. Moreover, regarding the design of the study on NLCR in bacterial sepsis by de Jager et al. [19], an important difference with the present study has to be taken into account. In the former study, lymphocytopenia and the NLCR were evaluated as predictors of the presence of bacteraemia in patients with suspected community-acquired bacteraemia, while in the present study these biomarkers were evaluated in a patient group with confirmed malaria. Considering this, the correlation of NLCR with peripheral parasite count and the fact that lymphocyte count increases and NLCR decreases after complete parasite clearance are

Table 3 Leukocyte count changes during malaria treatment

\begin{tabular}{|c|c|c|c|c|}
\hline & On admission & Upon clearance of parasitaemia & n & $P$ value \\
\hline \multicolumn{5}{|l|}{ Severe $P$. falciparum } \\
\hline $\mathrm{CRP}, \mathrm{mg} / \mathrm{L}$ & $184(108-373)$ & $49(1-206)$ & 29 & $<0.0001$ \\
\hline Total leukocyte count, $\times 10^{9} / \mathrm{L}$ & $6.8(2.5-18.5)$ & $7.8(3.1-16.4)$ & 40 & 0.0045 \\
\hline Neutrophil count, $\times 10^{9} / \mathrm{L}$ & $3.5(1.2-10.4)$ & $4.0(1.4-10.7)$ & 40 & NS \\
\hline Lymphocyte count, $\times 10^{9} / \mathrm{L}$ & $0.9(0.2-4.2)$ & $2.1(0.2-5.8)$ & 40 & $<0.0001$ \\
\hline NLCR & $4.0(0.9-17.0)$ & $2.1(0.5-20.3)$ & 40 & 0.0011 \\
\hline \multicolumn{5}{|l|}{ Non-severe $P$. falciparum } \\
\hline CRP, mg/L & $96(5-284)$ & $14(1-250)$ & 116 & $<0.0001$ \\
\hline Total leukocyte count, $\times 10^{9} / \mathrm{L}$ & $4.8(1.3-13.4)$ & $5.6(2.2-16.9)$ & 161 & $<0.0001$ \\
\hline Neutrophil count, $\times 10^{9} / \mathrm{L}$ & $3.0(0.6-8.8)$ & $2.5(0.3-11.9)$ & 114 & 0.0075 \\
\hline Lymphocyte count, $\times 10^{9} / \mathrm{L}$ & $0.9(0.2-3.1)$ & $2.0(0.3-4.5)$ & 114 & $<0.0001$ \\
\hline NLCR & $3.3(0.5-19.0)$ & $1.3(0.3-11.0)$ & 114 & $<0.0001$ \\
\hline
\end{tabular}


interesting findings; although NLCR lacks diagnostic power to accurately identify patients with severe malaria, a high parasite load does seem to result in relative lymphocytopenia.

Surprisingly for such a common phenomenon [3-7,21] the mechanism behind malaria-associated lymphopenia has still not been satisfactorily elucidated and remains the subject of debate [22]. The rapid re-emergence of lymphocytes in the peripheral circulation following initiation of treatment has led some authors to suggest transient sequestration during malaria to be responsible $[4,5]$. The relatively large drop in peripheral lymphocyte numbers would suggest this to be a non-specific effect, e.g. pooling in the enlarged spleens of patients [5] rather than a response by malaria-specific lymphocytes only. Others have pointed to the increased propensity of lymphocytes from malaria patients to undergo spontaneous apoptosis in vitro [23,24], possibly induced by soluble Fas ligand (sFasL)-Fas interaction [25]. Interestingly, increased apoptosis is also seen in healthy donors from endemic areas, be it to a lesser extent $[23,24,26]$, suggesting chronic stimulation of lymphocytes by environmental micro-organisms may be contributing through activation-induced cell death. Presumably both mechanisms are at work in tandem, with activated lymphocytes sequestering during malaria and rates of apoptosis, whether spontaneous or activation-induced, rising due to infection and peaking following treatment in order to restore homeostasis [27].

In conclusion, the NLCR was found to correlate with parasitaemia, but both lymphocytopenia and the NLCR were inferior to CRP as markers of severe disease in patients with imported malaria in direct back-to-back comparisons. Although these parameters may have proven their usefulness in predicting bacteraemia, they are apparently not useful as predictive markers of severe disease in imported malaria in the acute care setting.

\section{Competing interests}

The authors declare that they have no competing interests.

\section{Authors' contributions}

MEVW contributed to data acquisition and analysis and writing of the manuscript. KV, MdeMM, PCW, MBM and JVH participated in data analysis and revising the manuscript. RK was responsible for collection of patient data and database management. PJvG participated in study design, data analysis and writing and revising the manuscript. All authors have approved the final version of the manuscript.

\section{Acknowledgements}

The Port of Rotterdam is thanked for the unconditional financial grant to study travel-related imported infectious diseases in Rotterdam, The Netherlands.

\section{Author details}

1 Department of Internal Medicine, Harbour Hospital Rotterdam, Rotterdam, The Netherlands. ${ }^{2}$ Department of Medical Microbiology and Infection Control, Jeroen Bosch Hospital, 's-Hertogenbosch, The Netherlands. ${ }^{3}$ Department of Medical Microbiology and Infectious Diseases, Erasmus MC, Rotterdam, The Netherlands. ${ }^{4}$ Laboratory of Parasitology, Harbour Hospital and Institute for Tropical Diseases, Rotterdam, The Netherlands. ${ }^{5}$ Institute for
Tropical Diseases, Harbour Hospital Rotterdam, Haringvliet 72, 3011, TG Rotterdam, The Netherlands. ${ }^{6}$ Travel Clinic Havenziekenhuis, Rotterdam, The Netherlands.

Received: 31 December 2012 Accepted: 9 March 2013

Published: 18 March 2013

\section{References}

1. Akinosoglou KS, Solomou EE, Gogos CA: Malaria: a haematological disease. Hematology 2012, 17:106-114.

2. McKenzie FE, Prudhomme WA, Magill AJ, Forney JR, Permpanich B, Lucas C, Gasser RA Jr, Wongsrichanalai C: White blood cell counts and malaria. J Infect Dis 2005, 192:323-330.

3. Lisse IM, Aaby P, Whittle H, Knudsen K: A community study of $3 \mathrm{~T}$ lymphocyte subsets and malaria parasitaemia. Trans $R$ Soc Trop Med Hyg 1994, 88:709-710.

4. Hviid L, Kurtzhals JA, Goka BQ, Oliver-Commey JO, Nkrumah FK, Theander TG: Rapid reemergence of T cells into peripheral circulation following treatment of severe and uncomplicated Plasmodium falciparum malaria. Infect Immun 1997, 65:4090-4093.

5. Wyler DJ: Peripheral lymphocyte subpopulations in human falciparum malaria. Clin Exp Immunol 1976, 23:471-476.

6. Kassa D, Petros B, Mesele T, Hailu E, Wolday D: Characterization of peripheral blood lymphocyte subsets in patients with acute Plasmodium falciparum and $P$. vivax malaria infections at Wonji Sugar Estate, Ethiopia. Clin Vaccine Immunol 2006, 13:376-379.

7. Richards MW, Behrens RH, Doherty JF: Hematologic changes in acute, imported Plasmodium falciparum malaria. Am J Trop Med Hyg 1998, 59:859.

8. Ladhani S, Lowe B, Cole AO, Kowuondo K, Newton CR: Changes in white blood cells and platelets in children with falciparum malaria: relationship to disease outcome. Br J Haematol 2002, 119:839-847.

9. Wyllie $\mathrm{DH}$, Bowler IC, Peto TE: Relation between lymphopenia and bacteraemia in UK adults with medical emergencies. J Clin Pathol 2004, 57:950-955

10. Hawkins CA, Collignon P, Adams DN, Bowden FJ, Cook MC: Profound lymphopenia and bacteraemia. Intern Med J 2006, 36:385-388.

11. Seebach JD, Morant R, Ruegg R, Seifert B, Fehr J: The diagnostic value of the neutrophil left shift in predicting inflammatory and infectious disease. Am J Clin Pathol 1997, 107:582-591.

12. Rainer TH, Chan TY, Cocks RA: Do peripheral blood counts have any prognostic value following trauma? Injury 1999, 30:179-185.

13. Menges T, Engel J, Welters I, Wagner RM, Little S, Ruwoldt R, Wollbrueck M, Hempelmann G: Changes in blood lymphocyte populations after multiple trauma. Crit Care Med 1999, 27:733-740.

14. Zahorec R: Ratio of neutrophil to lymphocyte counts - rapid and simple parameter of systemic inflammation and stress in critically ill. Bratis/ Lek Listy 2001, 102:5-14.

15. de Jager CP, Wever PC, Gemen EF, Kusters R, van Gageldonk-Lafeber AB, van der Poll T, Laheij RJ: The neutrophil-lymphocyte count ratio in patients with community-acquired pneumonia. PLoS One 2012, 7:e46561

16. WHO: Guidelines for the treatment of malaria. World Health Organization; 2010 [http://www.who.int/malaria/publications/atoz/9789241547925/en/ index.html]

17. van Genderen PJ, Hesselink DA, Bezemer JM, Wismans PJ, Overbosch D: Efficacy and safety of exchange transfusion as an adjunct therapy for severe Plasmodium falciparum malaria in nonimmune travelers: a 10-year single-center experience with a standardized treatment protocol. Transfusion 2010, 50:787-794.

18. Hanley JA, McNeil BJ: The meaning and use of the area under a Receiver Operating Characteristic (ROC) curve. Radiology 1982, 143:29-36

19. de Jager CP, van Wijk PT, Mathoera RB, de Jongh-Leuvenink J, van der Poll T, Wever PC: Lymphocytopenia and neutrophil-lymphocyte count ratio predict bacteremia better than conventional infection markers in an emergency care unit. Crit Care 2010, 14:R192.

20. Bruneel F, Tubach F, Corne P, Megarbane B, Mira JP, Peytel E, Camus C, Schortgen F, Azoulay E, Cohen Y, Georges H, Meybeck A, Hyvernat H, Trouillet JL, Frenoy E, Nicolet L, Roy C, Durand R, Le Bras J, Wolff M: Severe imported falciparum malaria: a cohort study in 400 critically ill adults. PLoS One 2010, 5:e13236.

21. De Mast Q, Sweep FC, McCall M, Geurts-Moespot A, Hermsen C, Calandra T, Netea MG, Sauerwein RW, van der Ven AJ: A decrease of plasma 
macrophage migration inhibitory factor concentration is associated with lower numbers of circulating lymphocytes in experimental Plasmodium falciparum malaria. Parasite Immunol 2008, 30:133-138.

22. Hviid L, Kemp K: What is the cause of lymphopenia in malaria? Infect Immun 2000, 68:6087-6089.

23. Baldé AT, Sarthou JL, Roussilhon C: Acute Plasmodium falciparum infection is associated with increased percentages of apoptotic cells. Immunol Lett 1995, 46:59-62.

24. Toure-Balde A, Sarthou JL, Aribot G, Michel P, Trape JF, Rogier C, Roussilhon C: Plasmodium falciparum induces apoptosis in human mononuclear cells. Infect Immun 1996, 64:744-750.

25. Kern P, Dietrich M, Hemmer C, Wellinghausen N: Increased levels of soluble Fas ligand in serum in Plasmodium falciparum malaria. Infect Immun 2000, 68:3061-3063.

26. Kemp K, Akanmori BD, Hviid L: West African donors have high percentages of activated cytokine producing $T$ cells that are prone to apoptosis. Clin Exp Immunol 2001, 126:69-75.

27. Kemp K, Akanmori BD, Adabayeri V, Goka BQ, Kurtzhals JA, Behr C, Hviid L: Cytokine production and apoptosis among $T$ cells from patients under treatment for Plasmodium falciparum malaria. Clin Exp Immunol 2002, 127:151-157.

doi:10.1186/1475-2875-12-101

Cite this article as: van Wolfswinkel et al:: Predictive value of

lymphocytopenia and the neutrophil-lymphocyte count ratio for severe imported malaria. Malaria Journal 2013 12:101.

\section{Submit your next manuscript to BioMed Central and take full advantage of:}

- Convenient online submission

- Thorough peer review

- No space constraints or color figure charges

- Immediate publication on acceptance

- Inclusion in PubMed, CAS, Scopus and Google Scholar

- Research which is freely available for redistribution 